NASA/TM-2000-210478

AIAA-2000-3441

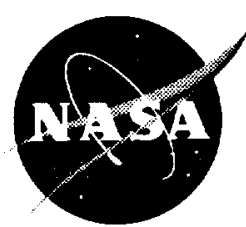

\title{
Planned Axial Reorientation Investigation on Sloshsat
}

David J. Chato

Glenn Research Center, Cleveland, Ohio 
The NASA STI Program Office ... in Profile

Since its founding, NASA has been dedicated to the advancement of aeronautics and space science. The NASA Scientific and Technical Information (STI) Program Office plays a key part in helping NASA maintain this important role.

The NASA STI Program Office is operated by Langley Research Center, the Lead Center for NASA's scientific and technical information. The NASA STI Program Office provides access to the NASA STI Database, the largest collection of aeronautical and space science STI in the world. The Program Office is also NASA's institutional mechanism for disseminating the results of its research and development activities. These results are published by NASA in the NASA STI Report Series, which includes the following report types:

- TECHNICAL PUBLICATION. Reports of completed research or a major significant phase of research that present the results of NASA programs and include extensive data or theoretical analysis. Includes compilations of significant scientific and technical data and information deemed to be of continuing reference value. NASA's counterpart of peerreviewed formal professional papers but has less stringent limitations on manuscript length and extent of graphic presentations.

- TECHNICAL MEMORANDUM. Scientific and technical findings that are preliminary or of specialized interest, e.g., quick release reports, working papers, and bibliographies that contain minimal annotation. Does not contain extensive analysis.

- CONTRACTOR REPORT. Scientific and technical findings by NASA-sponsored contractors and grantees.
- CONFERENCE PUBLICATION. Collected papers from scientific and technical conferences, symposia, seminars, or other meetings sponsored or cosponsored by NASA.

- SPECIAL PUBLICATION. Scientific, technical, or historical information from NASA programs, projects, and missions, often concerned with subjects having substantial public interest.

- TECHNICAL TRANSLATION. Englishlanguage translations of foreign scientific and technical material pertinent to NASA's mission.

Specialized services that complement the STI Program Office's diverse offerings include creating custom thesauri, building customized data bases, organizing and publishing research results ... even providing videos.

For more information about the NASA STI Program Office, see the following:

- Access the NASA STI Program Home Page at http://www.sti.nasa.gov

- E-mail your question via the Internet to help@sti.nasa.gov

- Fax your question to the NASA Access Help Desk at (301) 621-0134

- Telephone the NASA Access Help Desk at (301) 621-0390

- Write to: NASA Access Help Desk NASA Center for AeroSpace Information 7121 Standard Drive Hanover, MD 21076 
NASA/TM-2000-210478

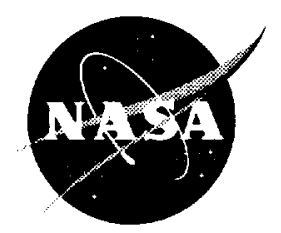

\section{Planned Axial Reorientation Investigation on Sloshsat}

David J. Chato

Glenn Research Center, Cleveland, Ohio

Prepared for the

36th Joint Propulsion Conference and Exhibit cosponsored by the AIAA, ASME, SAE, and ASEE

Huntsville, Alabama, July 16-19, 2000

National Aeronautics and

Space Administration

Glenn Research Center 


\section{Acknowledgments}

The author wishes to thank Professor John Hochstein of the University of Memphis and his graduate student, Curtis Duncan, for the CFD analysis of SLOSHSAT. The author also wishes to acknowledge NLR for figure 1.

Available from

NASA Center for Aerospace Information

7121 Standard Drive

Hanover, MD 21076

Price Code: A03
National Technical Information Service 5285 Port Royal Road Springfield, VA 22100

Price Code: A03

Available electronically at http://gltrs.grc.nasa.gov/GLTRS 


\title{
PLANNED AXIAL REORIENTATION INVESTIGATION ON SLOSHSAT
}

\author{
David J. Chato" \\ National Aeronautics and Space Administration \\ Glenn Research Center \\ Cleveland, Ohio 44135
}

\begin{abstract}
This paper details the design and logic of an experimental investigation to study axial reorientation in low gravity. The Sloshsat free-flyer is described. The planned axial reorientation experiments and test matrixes are presented. Existing analytical tools are discussed. Estimates for settling range from 64 to 1127 seconds. The planned experiments are modelled using computational fluid dynamics. These models show promise in reducing settling estimates and demonstrate the ability of pulsed high thrust settling to emulate lower thrust continuous firing.
\end{abstract}

\section{INTRODUCTION}

The European Space Agency (ESA) in conjunction with the Netherlands Agency for Aerospace Programs has undertaken a project to investigate fluid motion in zero-g. ESA has contracted with the Netherlands National Aerospace Laboratory (Nationaal Lucht-en Ruimtevaartlaboratorium or NLR) for a small free flying spacecraft deployed from the shuttle but flying in tandem with it. This spacecraft is known as the Sloshsat Facility for Liquid Experimentation and Verification On-orbit (Sloshsat FLEVO or just Sloshsat for short). The ESA/NLR investigators have concentrated on studying the effect of liquid motions on spinning spacecraft. NASA has spent several years investigating the low gravity maneuvers to settle propellants prior to restarting engines in space after a low gravity coast. These maneuvers involve using an axial thrust to create a simulated gravity forcing the propellant to the "bottom" of the tank. Although these maneuvers have been extensively studied in drop-towers and by analysis, little flight data exists. Sloshsat is an ideal platform to obtain the long term low-gravity data necessary to confirm the findings of the analytical work and drop tower tests. This paper will discus the experiments planned for Sloshsat to study these maneuvers.

\footnotetext{
"Senior Member, AIAA.
}

\section{NOMENCLATURE}

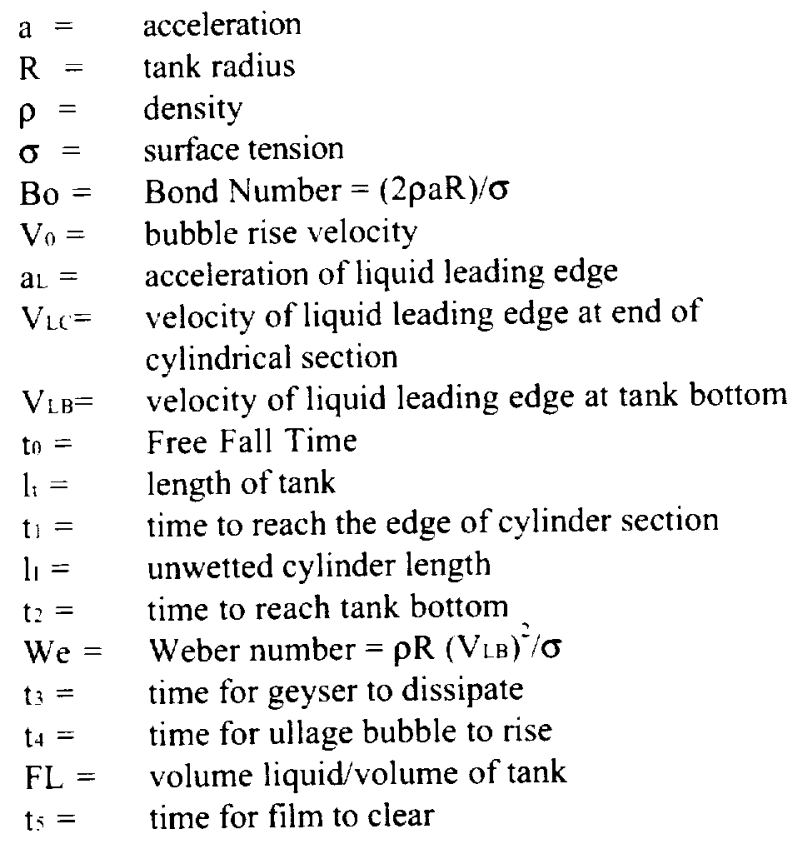

\section{BACKGROUND}

Most liquid fueled rocket engines require a continuous supply of liquid propellant to function. Low gravity challenges these engines since the lack of separation between liquid and gas will allow gas ingestion into an engine, possibly resulting in catastrophic failure of that engine. However. coasting in the low gravity environment for long periods of time ( $1 / 2$ hour to days) is required by most upper stage rockets to correctly position their payloads. Prior to restarting the engines of these rockets, something must be done to assure gas free liquid to the engines.

Many solutions to this problem have been implemented in the past. The Saturn moon rocket used propulsive venting of the boil-off from its cryogenic 
propellant tanks to provide a continuous settling thrust. The Centaur upper stage uses an auxiliary propulsion system to settle the liquid prior to engine start. Many satellites use various liquid acquisition devices that rely on surface tension forces to separate the liquid and gas.

Because of its involvement in the Centaur program and its interest in low-gravity fluid behavior, the NASA Glenn has conducted extensive research on the settling thrust maneuver. Lacovic et al.' explain the Centaur system as well as the difficulties encountered during its development. The Centaur uses $27 \mathrm{~N}$ of thrust to settle (at settling Bond number of 360 ). In parallel with the Centaur development the settling maneuver was investigated in the drop towers. Key papers include Masica and Petrash, ${ }^{2}$ Salzman and Masica. ${ }^{3}$ and Salzman, Masica, and Lacovic. ${ }^{4}$ Work in the drop tower suggests that far less thrust than is currently used would be capable of equivalent settling times. This is due to the following phenomena. Much of the energy used to start the fluid motion is stored as momentum in the bulk liquid. When the liquid reaches the bottom of the tank, this momentum causes the moving liquid to rebound as a geyser along the tank centerline. High thrust levels can even cause the falling liquid to entrain large quantities of gas. Sumner ${ }^{5}$ revisited the tests of the Centaur development era to minimize the total impulse used for settling maneuvers. His work suggested that the optimum settling thrusts generate Bond numbers on the order of 4 to 6 (rather than 360), but lower thrust levels have not been used since the small thrusters required are not readily available. There was also the problem that at these Bond numbers the low gravity time available from drop tower testing was insufficient to observe the liquid settle to its final quiescent state, so estimates of settling time were extrapolated.

The advance of digital computer technology has allowed the low gravity fluids problem to be addressed via a different approach, analytical modeling on the computer. Several techniques have been developed to model low-gravity fluid motion. The large distortion of the free surface during reorientation makes it difficult to model with a continuous free surface treatment, but several discrete methods have been evolved that are fairly successful. First the marker and cell algorithm which follows tracer particles and then with the volume of fluid codes which move to a continuum within the bulk liquid while retaining the discrete nature at the free surface. Reorientation and settling have been used as a test case for these codes because the axial symmetry of the problem allow it to be addressed with a two dimensional code. Lacovic ${ }^{6}$ was able to compare the simplified cell and marker code ERIE (Bradshaw and Kramer, Bradshaw, Kramer, and Zich ${ }^{8}$ ) results to the Titan/Centaur flight data and show a favorable comparison. Hochstein, Patag, and Chato ${ }^{9}$ were able to match the work of Sumner ${ }^{5}$ with a modified version of NASA-VOF2D (Torrey et al. ${ }^{10}$ ). Continuing that work, Hochstein et al. " were able to suggest that intermittent firing of large thrusters may be capable of emulating lower thrust levels since the liquid will act as an integrating media (i.e. liquid continues to settle even after thrust stops due to the conservation of momentum).

\section{OBJECTIVES}

The objectives of the NASA Sloshsat experiment are: -Demonstrate that propellant can be settled at low $(B o<12)$ thrust levels

-Observe that pulsed thruster firing can be used to emulate lower thrust settling due to the integration effect of bulk liquid motion -Confirm that the drop tower investigation represents a realistic prediction of long term low-gravity motion.

\section{JUSTIFICATION}

In-space low-gravity is the only environment in which surface tension effects on propellant settling can be observed on a time scale large enough to be meaningful. Drop tower time is insufficient to observe the total process, and parabolic aircraft flight cannot generate stable low-g conditions. Settling in current rocket stages uses thrust far in excess of what is actually required to settle the propellent. This high thrust not only wastes propellant but may also slow settling time by imparting too much kinetic energy to the bulk liquid.

\section{DESCRIPTION OF EXPERIMENT}

\section{Spacecraft}

The SLOSHSAT is a free flying spacecraft launched from a cross-bay Hitchhiker bridge attached to the Space Shuttle. The primary test-bed is an 87-liter composite tank filled with 33.5 liters of deionized water. Platinum wire rings embedded in the tank wall measure capacitance at 270 locations throughout the tank. This information is used to determine liquid height over the location to a maximum of $0.03 \mathrm{~m}$. Sensors at three locations provide information on finer resolution information on liquid height. Miniature 
thermal dispersion meters provide velocity measurements at 10 locations in the tank. A cold gas thruster system fed by four gaseous nitrogen tanks allows the tank to be maneuvered through a broad range of motions. Twelve $0.8 \mathrm{~N}$ thrusters provide the ability to translate in all three directions and rotate about all three axes Six accelerometers and 3 gyroscopes provide detailed information on SLOSHSAT motion. An on-board telemetry system relays experiment data back to the Space Shuttle for transmission to the ground. Figure 1 shows the interior of the SLOSHSAT.

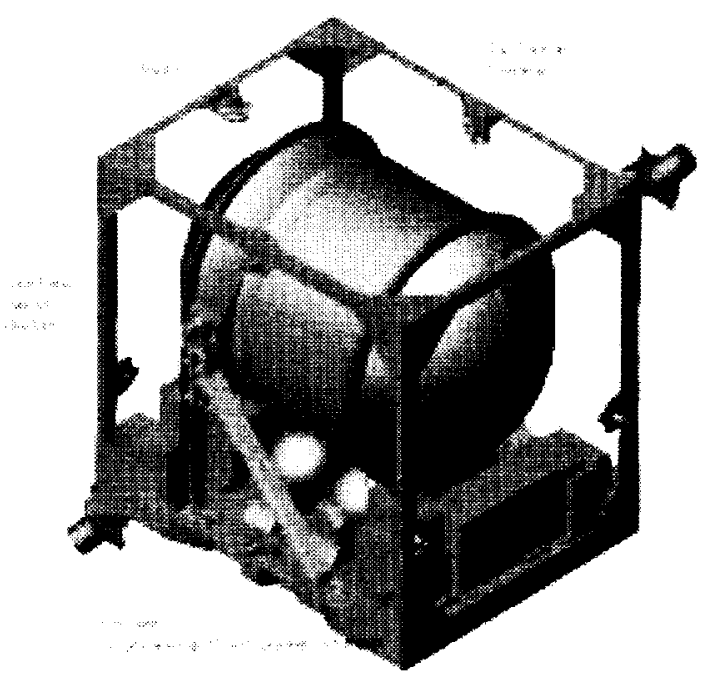

Figure 1. SLOSHSAT interior.

This experiment will use the SLOSHSAT to perform axial settling maneuvers. The instrumentation for SLOSHSAT will provide information on the acceleration environment, position of the leading edge, and approach of the ullage bubble to the top wall. The thrusters are sized to produce an acceleration equivalent to a Bond number of 12 in the test tank, since this is the limit for bubble rise velocity. In addition the Shuttle primary reaction control system (RCS) will be used to perform maneuvers while SLOSHSAT is still attached to the Space Shuttle. Sloshsat instrumentation will be used for these maneuvers also.

\section{Experimental Procedure}

The axial reorientation will settle liquid in the tank by firing thrusters to accelerate along the tank long axis. To start the test, thrust in reverse direction will position the liquid in a known adverse configuration. Planned tests are shown in table 1. Effective Bo is calculated by averaging acceleration over the duration of the test.
Table 1. Matrix of test.

\begin{tabular}{|l|l|l|l|l|}
\hline Id & $\begin{array}{c}\text { Accel; } \\
\left(\mathrm{cm} / \mathrm{s}^{2}\right)\end{array}$ & \multicolumn{1}{|c|}{$\begin{array}{c}\text { Pulse } \\
(\mathrm{sec})\end{array}$} & Frequency & $\begin{array}{c}\text { Effective } \\
\text { Bo }\end{array}$ \\
\hline 0 & 7.84 & Continuous & N/A & 56.6 \\
\hline 1 & 7.84 & 0.2 & $1 \mathrm{hz}$ & 12 \\
\hline 2 & 7.84 & 0.1 & $1 \mathrm{hz}$ & $6^{*}$ \\
\hline 3 & 7.84 & 4 & Once & $12^{*}$ \\
\hline 4 & 7.84 & 2 & Once & 6 \\
\hline 5 & 1.67 & Continuous & $\mathrm{N} / \mathrm{A}$ & 12 \\
\hline 6 & 0.83 & Continuous & $\mathrm{N} / \mathrm{A}$ & 6 \\
\hline 7 & 1.67 & .5 & $1 \mathrm{hz}$ & 6 \\
\hline 8 & 1.67 & .33 & $1 \mathrm{hz}$ & 4 \\
\hline
\end{tabular}

*Based on test time of $2 \mathrm{l}$ seconds.

The procedure for test 5 (a representative test) is as follows:

Objective: Settle Propellant in the constant bubble rise velocity regime $(\mathrm{Bo}=12)$

Sequence:

- Activate data acquisition system

-Accelerate along tank long axis using

$\mathrm{Bo}=12$ Thruster

-Ascertain absence of liquid motion

-Accelerate in reverse direction

-Ascertain absence of liquid motion

-Terminate test

\section{ANALYTICAL APPROACH}

Two sets of tools exist for analysis and prediction of the SLOSHSAT fluid motion: first, empirical correlations from drop tower testing and second, computational modelling of the fluid motion.

\section{Empirical Correlations}

The empirical correlations from drop tower research will be examined to predict times for fluid motion and estimate required regimes. Masica and Petrash explored the motion of vapor in inverted partially liquid filled long cylinders and were able to develop a correlation using the Bond number. This correlation agreed with both $1-\mathrm{g}$ and drop tower tests and reduced to the theoretical prediction for the rise rate of large bubbles in normal gravity once the bond number exceeded 12. Masica and Petrash give the ullage bubble rise rate as:

$\mathrm{V}_{0}=0.48(\mathrm{aR})^{1 / 2}\left[1-(0.84 / \mathrm{Bo})^{\mathrm{B} 04.7}\right]$ 
Which reduces to:

$$
\mathrm{V}_{0}=0.48(\mathrm{aR})^{1 / 2}
$$

when Bo is greater than 12 . Observation of the motion of the liquid leading edge resulted in its acceleration being correlated for Bo greater than 1.7as follows:

$\mathrm{aL}_{\mathrm{L}}=3.8 \mathrm{~V}_{0}{ }^{2} / \mathrm{R}$

Salzman and Masica ${ }^{3}$ investigated the motion of liquid in propellant tank models. Results for bubble rise velocity agree with equation 1 , but the leading edge motion had to be corrected for the effect of the spherical tank bottom. They used the following equation to determine leading edge velocity at the bottom of a concave spherical tank from the leading edge velocity at the end of the cylindrical section.

$$
V_{L B}=\left[V_{L C}{ }^{2}+2\left(a_{L} R\right)\right]^{1 / 2}
$$

They also observed that the liquid rebounded in a geyser along the tank center when Weber number based on this velocity and tank radius exceeded 4 . Sumner took the work of Salzman and Masica and developed a computer model to predict reorientation time. This model was used to prepare charts where the minimum velocity increment (that which requires least change in velocity, hence least acceleration and propellant) could be found graphically. Sumner ${ }^{5}$ suggests an optimum settling acceleration as that which produces a bond number between 3 and 5 depending on fill level. For the SLOSHSAT fill level of 0.39 the optimum bond number is about 4.5 .

\section{Settling Time}

Danzell $^{13}$ defines a characteristic time for settling as the time required for a particle on the tank wall to reach the opposite end of the tank. For a constant acceleration this time is given by $t_{0}=(2 \mathrm{l} / \mathrm{a})^{1 / 2}$

He suggests that in 3 times this interval the majority of the liquid will have settled. Traditionally spacecraft designers have used 5 times this time as a conservative estimate of settling time. Sumner ${ }^{5}$ defines several other important times. The time for the leading edge of the liquid to reach the end of the tank cylinder section is given by

$\mathrm{t}_{1}=2 / \mathrm{VLC}_{\mathrm{LC}}\left(\mathrm{l}_{1}\right)^{1 / 2}\left(\mathrm{l}_{1}+\mathrm{R}\right)^{1 / 2}$

the additional time to reach the tank bottom is

$\mathrm{t}_{2}=2\left(\mathrm{l}_{\mathrm{l}}+\mathrm{R}\right) / \mathrm{V}_{\mathrm{Lc}} \times\left[1-\left(\mathrm{l}_{\mathrm{l}} / \mathrm{l}_{\mathrm{l}}+\mathrm{R}\right)\right]^{1 / 2}$

When a strong geyser occurs the time for the geyser to damp is estimated from limited empirical data as

$t_{3}=0.0516 \times$ Bo $\times$ We $\left(\rho R^{3} / \sigma\right)^{1 / 2}$

The time for the ullage bubble to rise to the top of the tank is

$\mathrm{t}_{4}=\left(\mathrm{l}_{\mathrm{c}}-\mathrm{l}_{\mathrm{I}}\right) / \mathrm{V}_{0}$

The time for the liquid film to clear the tank wall is

$\mathrm{t} s=2\left(\mathrm{l}_{\mathrm{s}}+\mathrm{R} / \mathrm{V}_{1}\right)$

where:

$\mathrm{l} J=[(1 / 2 \mathrm{R}-1)-\mathrm{FL}(\mathrm{l} / 2 \mathrm{R}-1 / 3)+1 / 3] 2 \mathrm{R}$

The total settling time is the greater of five times to, $t_{1}+t_{2}+t_{3}$ or $t_{1}+t_{s}$. Predicted Settling Times for SLOSHSAT accelerations are tabulated in table 2 .

Table 2. SLOSHSAT time scales (seconds).

\begin{tabular}{|l|l|l|l|l|l|l|l|l|l|l|}
\hline Bo & $t_{0}$ & $t_{1}$ & $t_{2}$ & $t_{3}$ & $t_{4}$ & $t_{s}$ & $\begin{array}{l}\text { Geyser } \\
\text { damp }\end{array}$ & $\begin{array}{l}\text { Bubble } \\
\text { Rise }\end{array}$ & $\begin{array}{l}5 \text { times } \\
\text { free-fall }\end{array}$ & Max t \\
\hline 57 & 4.18 & 0.58 & 2.13 & 1124 & 3.20 & 8.87 & 1127 & 12.1 & 21 & 1127 \\
\hline 12 & 9.06 & 1.25 & 4.61 & 184 & 6.94 & 19.2 & 190.4 & 26.2 & 45 & 190.4 \\
\hline 6 & 12.8 & 1.77 & 6.52 & 46.1 & 9.81 & 27.2 & 54.4 & 37.0 & 64 & 64 \\
\hline 4 & 15.7 & 2.17 & 7.99 & 20.5 & 12.0 & 33.3 & 30.7 & 45.3 & 78 & 78 \\
\hline
\end{tabular}




\section{Computational Model}

The equations above yield a prediction of gross fluid motion and estimates of settling time. To refine these analyses and demonstrate the integrating effect of the bulk liquid during intermittent thrust, computational fluid dynamics were run to predict fluid motion. Figure 2 shows the computational grid and starting fluid position. Figures 3 to 10 show time histories of the free surface and velocity vectors for various planned Sloshsat tests. All tests have been analyzed. Tests 3 and 4 are not shown since these did not settle but oscillated about the free surface shape of figure $2 b$. The code used was ECLIPSE, which has a long history of use with reorientation problems. ECLIPSE solves the Naiver Stokes equation using a Volume of Fluid Approach. A color function is used to track the free surface position. Free surface forces are approximated in this version of ECLIPSE by the method of Kothe. ${ }^{14}$ Heavy black lines show the tank wall and free surface location(s). Fine lines show vectors of velocity. Since in each image the vectors are scaled from the maximum in that image, they should be viewed for qualitative rather than quantitative information. Unfortunately the CFD runs used yet a different settling criteria (the fluid was considered settled when the bottom $10 \%$ of the tank was filled with liquid) so they cannot be compared to the settling times of table 2 . They do correspond to the $t_{2}$ leading edge time fairly well. Figure 3 clearly illustrates the classic geyser problem. Note the similarities between figures 5,7 and 8 . These are all effective Bo of 6 . These agree closely in run time and fluid behavior.

\section{DATA ANALYSIS}

To reduce the SLOSHSAT data, the experimental low gravity information obtained will be compared to analytical predictions. Unfortunately due the limited range of the liquid height sensors liquid position cannot be determined by direct measurement. Liquid position will be inferred by the leading and trailing edge positions, the knowledge that since this is a closed system liquid volume is conserved, and the ECLIPSE analysis.
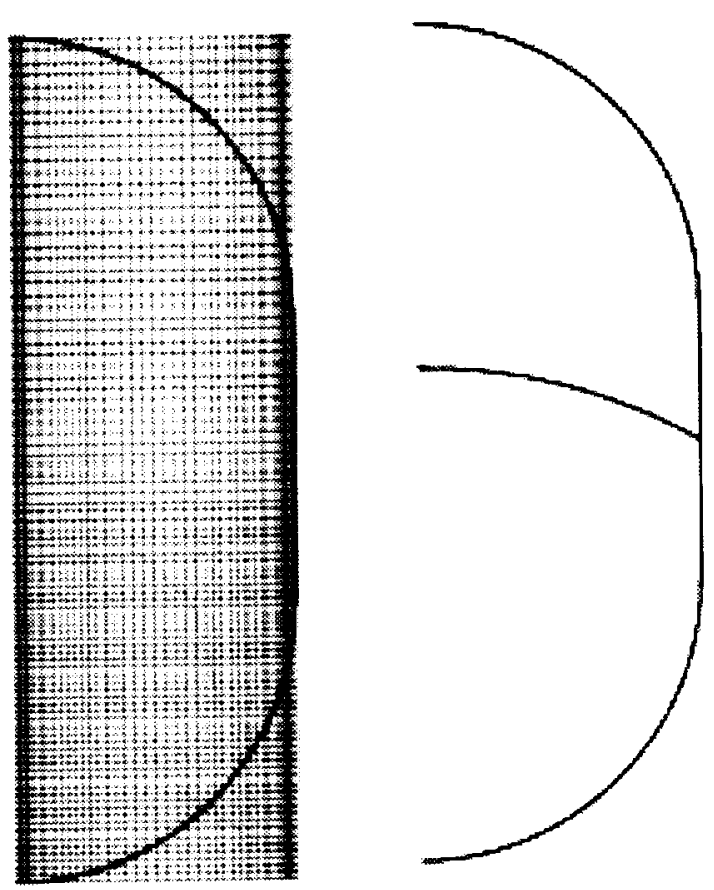

Figure 2. Initial conditions for calculation. a)Grid. b)Starting fluid position.
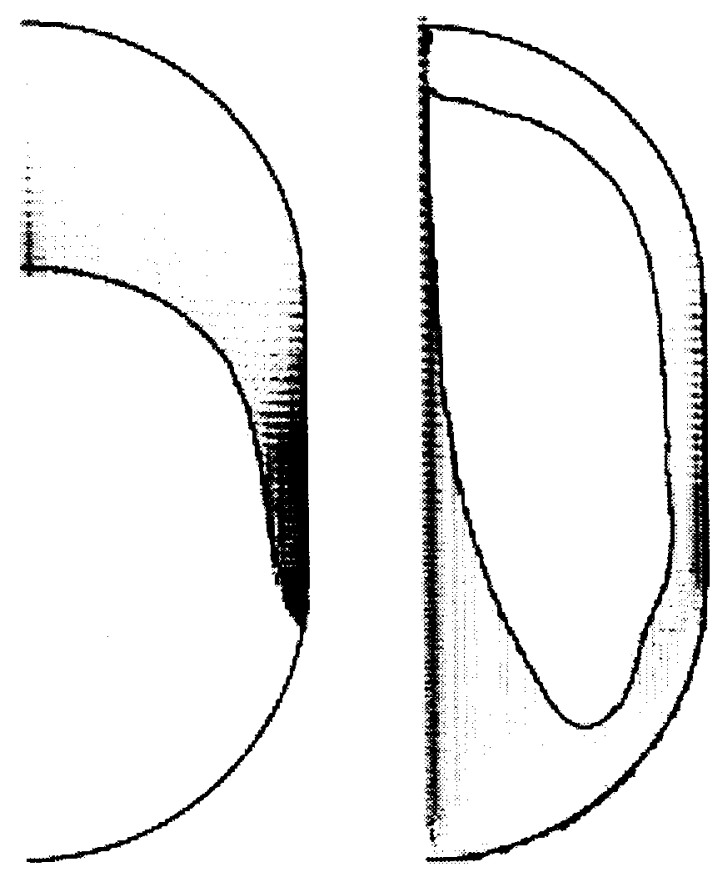

Figure 3. Bo $=56.6$ Full Shuttle RCS. a) 2.5 seconds. b) 5.5 seconds. 

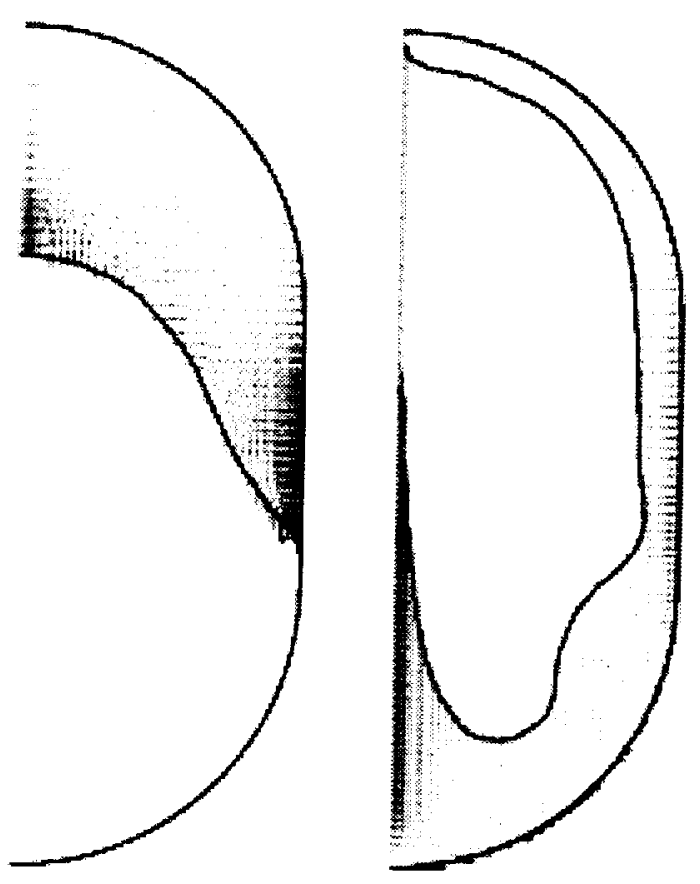

Figure 4. Full RCS pulsed on 0.2 seconds every second (effective $B o=12$ ).

a) 5 seconds. b) 12.2 seconds.
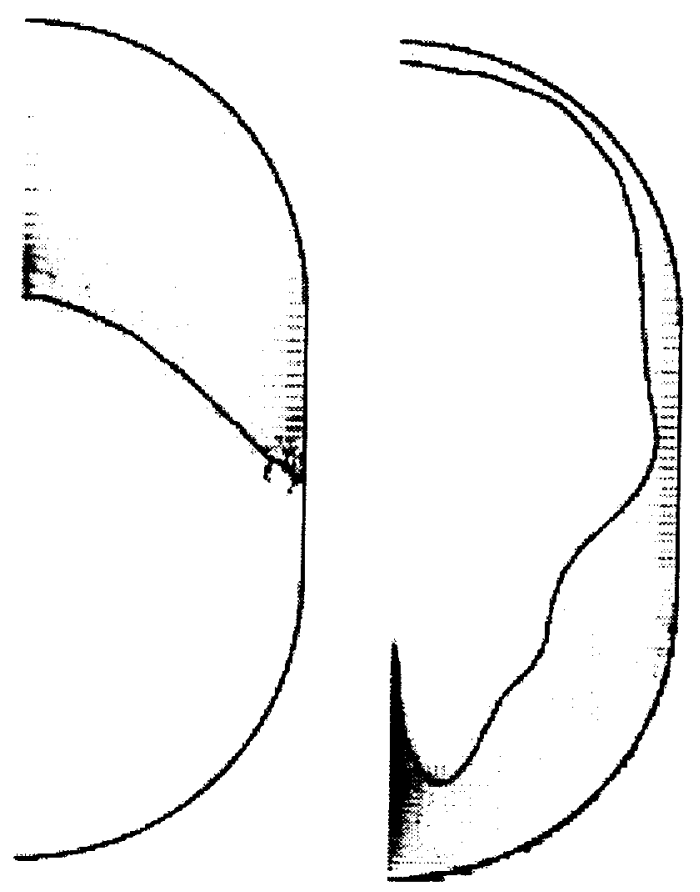

Figure 5. Full RCS pulsed on 0.1 seconds every second (effective $B=6$ ).

a) 5 seconds. b) 24.3 seconds.

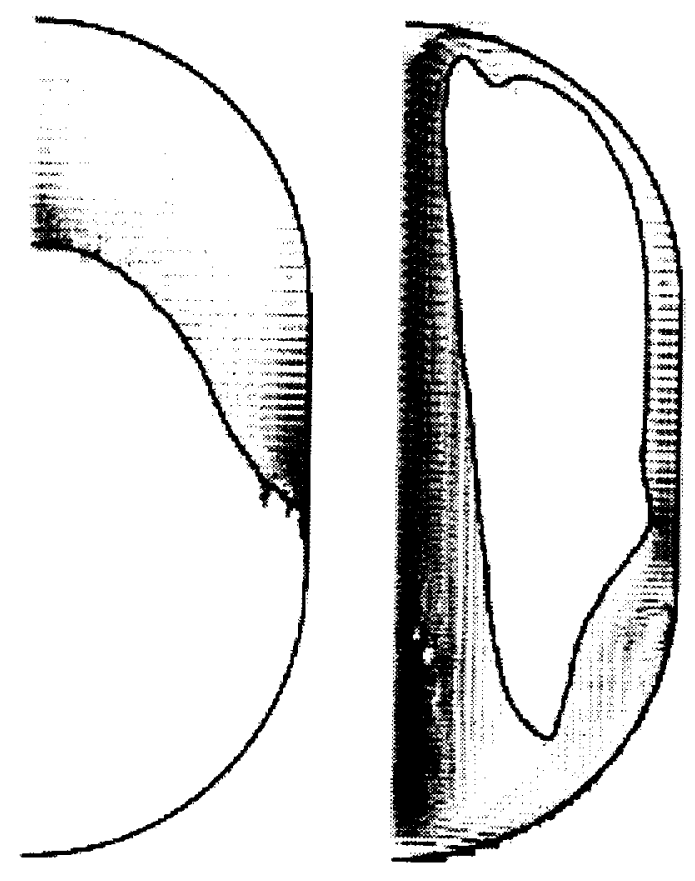

Figure 6. Two Sloshsat thrusters firing continuously for $B o=12$.

a) 5 seconds. b) 13.6 seconds.

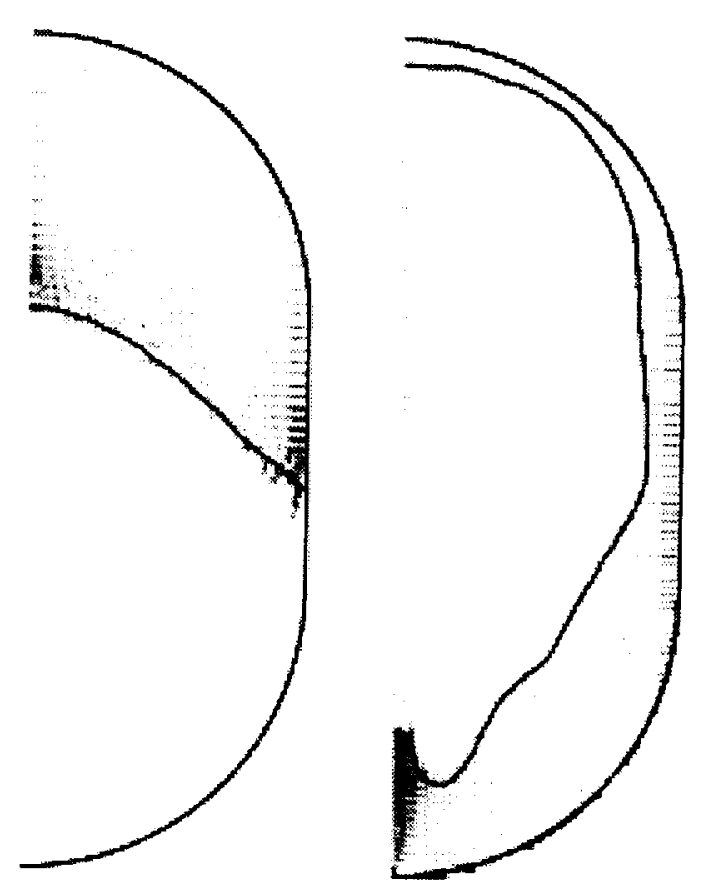

Figure 7. Two Sloshsat thrusters firing alternately for $B o=6$.

a) 5 seconds. b) 22.2 seconds. 

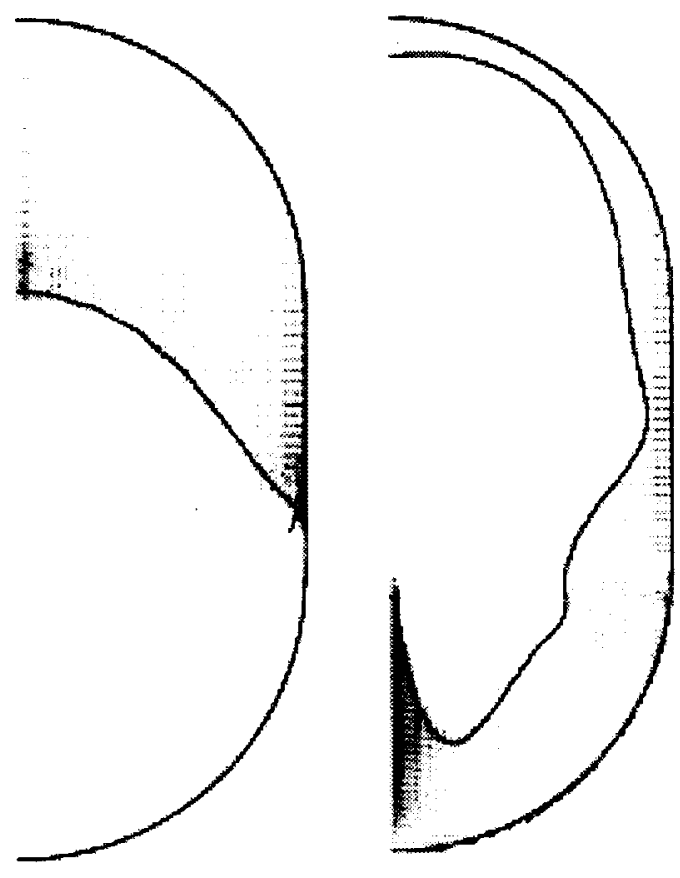

Figure 8. Two Sloshsat thrusters firing together for a 0.5 second pulse every second (effective $B o=6$ ). a) 5 seconds. b) 19.0 seconds.
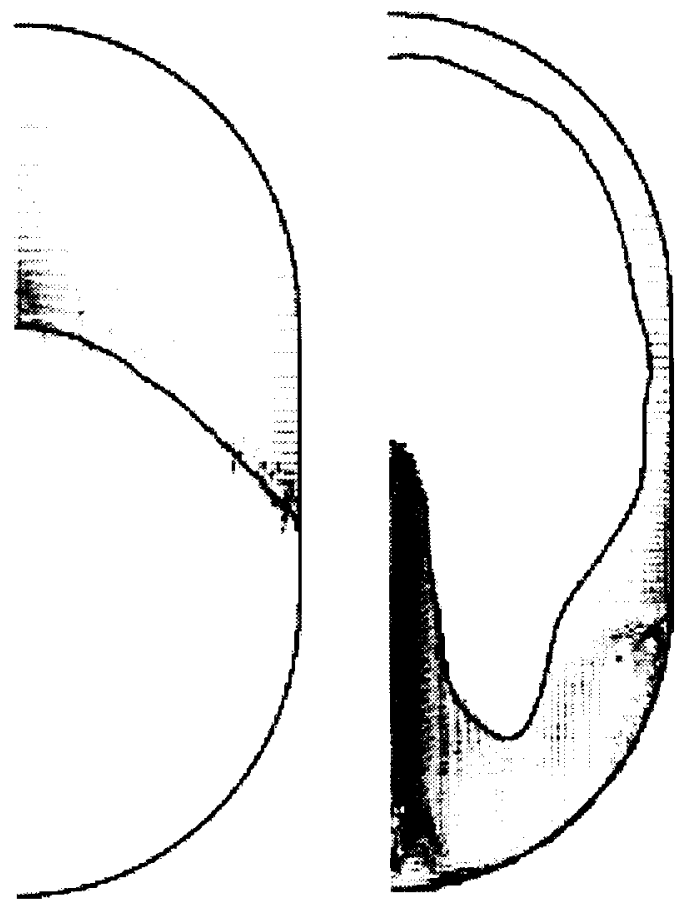

Figure 9. Two Sloshsat thrusters firing together for a 0.33 second pulse every Second (effective $B o=4$ ).

a) 5 seconds. b) 33.6 seconds.

\section{SUMMARY}

Existing analytical models are shown in this paper to predict very long times for liquid settling when geysers are formed. CFD analysis presented in this paper indicate the potential for reducing settling times by preventing geyser formation. CFD also shows how oversize thrusters can be pulsed to reduce geysering. However CFD alone is not sufficient, its findings must be validated by experimental results. SLOSHSAT provides an opportunity to obtain experimental results on fluid behavior during axial settling in the actual low-gravity environment. Objectives of the axial reorientation experiment are: demonstration that propellant can be settled at low thrust levels; observation whether pulsed thruster firing can be used to emulate lower thrust settling due to the integration effect of bulk liquid motion; and confirm that the drop tower investigation represent a realistic prediction of long term low-gravity motion. Accomplishing these objectives may radically reduce propellant consumption required for settling maneuvers.

\section{REFERENCES}

1. R.F. Lacovic, F.C. Yeh, S.V. Szabo Jr., R.J. Brun, A.J. Stofan, and J.A. Bems. "Management of Cryogenic Propellants in a Full-Scale Orbiting Space Vehicle." NASA TN D-4571. May 1968.

2. W.J. Masica and D.A. Petrash. "Motion of Liquid-Vapor Interface in Response to Imposed Acceleration." NASA TN D-3005. Sept. 1965.

3. J.A. Salzman and W.J. Masica. "Experimental Investigation of Liquid-Propellant Reorientation." NASA TN D-3789, Jan. 1967.

4. J.A. Salzman. W.J. Masica, and R.F. Lacovic. "Low-Gravity Reorientation in a Scale-Model Centaur Liquid Hydrogen Tank." NASA TN D-7168, Feb. 1973.

5. I.E. Sumner. "Liquid Propellant Reorientation in a Low-Gravity Environment." NASA TM-78969, July 1978.

6. R.F. Lacovic. "Centaur Zero Gravity Coast and Engine Restart Demonstration on the Titan/Centaur (TC-2) Extended Mission." NASA TM X-71821, Oct. 1975. 
7. R.D. Bradshaw and J.L. Kramer. "An Analytical Study of Reduced Gravity Propellant Settling." NASA CR-134593, Feb. 1974.

8. R.D. Bradshaw, J.L. Kramer and J.L. Zich. "An Analytical Study of Reduced-Gravity Flow Dynamics." NASA CR-135023, April 1976.

9. J.I. Hochstein, A.E. Patag, and D.J. Chato. "Modelling of Impulsive Propellant Reorientation." NASA TM-101440. Jan. 1989.

10. M.D. Torrey et al. "NASA-VOF2D: A Computer Program for Incompressible Flows with Free Surfaces." LA-10612-MS, Los Alamos National Laboratory, Dec. 1985.

11. J.I. Hochstein, A.E. Patag, T.P. Korakianitis, and D.J. Chato. "Pulsed Thrust Propellant Reorientation: Concept and Modeling." AIAA Journal of Propulsion and Power, Vol 8., No 4., July 1992.
12. J.I. Hochstein. "Computational Prediction of Propellant Motion During Separation of a Centaur G-Prime Vehicle from the Shuttle." Washington University in St. Louis, MO WU/CFDL-85/1, Dec. 1985.

13. J.F. Dalzell. "Liquid Impact on Tank Bulkheads" in The Dynamic Behavior of Liquids in Moving Containers. NASA SP-106. 1966.

14. D.B. Kothe, R.C. Mjolsness, and M.D. Torrey. "RIPPLE: A Computer Program for Incompressible Flows with Free Surfaces" Los Alamos National Laboratory LA-12007-MS, 1991. 


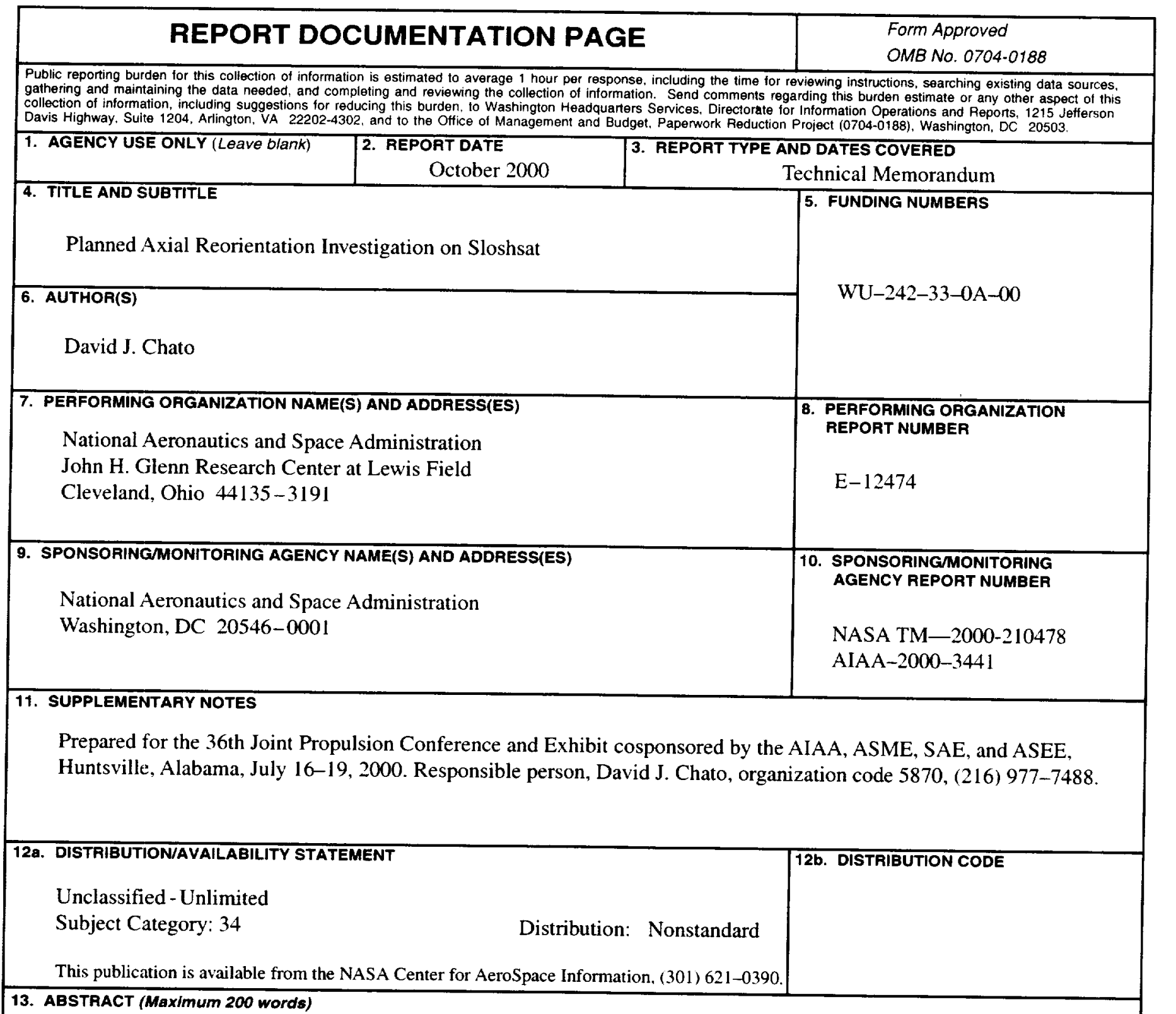

This paper details the design and logic of an experimental investigation to study axial reorientation in low gravity. The Sloshsat free-flyer is described. The planned axial reorientation experiments and test matrixes are presented. Existing analytical tools are discussed. Estimates for settling range from 64 to 1127 seconds. The planned experiments are modelled using computational fluid dynamics. These models show promise in reducing settling estimates and demonstrate the ability of pulsed high thrust settling to emulate lower thrust continuous firing.

14. SUBJECT TERMS

Fluid management; Low gravity; Propellants 15. NUMBER OF PAGES 14 16. PRICE CODE

\begin{tabular}{|c|c|}
\hline $\begin{array}{l}\text { 17. SECURITY CLASSIFICATION } \\
\text { OF REPORT } \\
\text { Unclassified }\end{array}$ & $\begin{array}{c}\text { 18. SECURITY CLASSIFICATION } \\
\text { OF THIS PAGE } \\
\text { Unclassified }\end{array}$ \\
\hline
\end{tabular}
9. SECURITY CLASSIFICATION OF ABSTRACT Unclassified 
